\title{
Perancangan Stasiun Televisi Daring untuk Memperluas Jangkauan Siar WalisongoTV
}

\author{
Masy Ari Ulinuhaํ, Akmal Irfan Maulana², Sarah Wijayanti³ ${ }^{3}$ Amelia Rahmi ${ }^{4}$, Kholifatul \\ Ardliyan $^{5}$ \\ 12345 Universitas Islam Negeri Walisongo
}

\begin{abstract}
WalisongoTV is a campus television of UIN Walisongo which has been pioneered by the Faculty of Da'wah and Communication since 2012. Walisongo TV is prepared as a community television that serves citizens of the UIN Walisongo and surrounding areas. The regulations place restrictions on a community broadcasting institution, so it is feared that WalisongoTV cannot operate optimally if it only relies on broadcasts. Along with the development of information technology, WalisongoTV can utilize the internet as its broadcast media. In this study, a web-based television station was designed to broadcast WalisongoTV. The method used in this study consisted of three stages, namely: designing the WalisongoTV website, designing video live streaming, and testing video live streaming. In its design, the station uses webblog facilities provided by Blogspot, uses Ustream as a streaming server, and uses VLC Player as a video player as well as to manage the screen display. This research has succeeded in creating a WalisongoTV webpage and successfully transmitting WalisongoTV broadcasts via live streaming video facilities.
\end{abstract}

Keywords:

Keyword : $\quad$ Online television station, Ustream, video live streaming, WalisongoTV.

\begin{abstract}
Abstrak
WalisongoTV merupakan televisi kampus UIN Walisongo yang telah dirintis oleh Fakultas Dakwah dan Komunikasi sejak tahun 2012. Walisongo TV dipersiapkan sebagai televisi komunitas yang melayani warga kampus UIN Walisongo dan sekitarnya. Ketentuan perundang-undangan banyak memberikan pembatasan pada sebuah lembaga penyiaran komunitas, sehingga dikhawatirkan WalisongoTV tidak dapat beroperasi secara maksimal jika hanya mengandalkan siaran broadcast. Seiring dengan perkembangan teknologi informasi, WalisongoTV dapat memanfaatkan internet sebagai media penyiarannya. Dalam penelitian ini, dirancang sebuah stasiun televisi berbasis web untuk memancarkan siaran WalisongoTV. Metode yang digunakan dalam penelitian ini terdiri dari tiga tahap yaitu: perancangan website WalisongoTV, perancangan video live streaming dan uji coba video live streaming. Dalam perancangannya, stasiun televisi yang dibuat memanfaatkan fasilitas webblog yang disediakan oleh Blogspot, menggunakan Ustream sebagai server streaming, dan memakai VLC Player sebagai pemutar video sekaligus mengatur tampilan layar WalisongoTV. enelitian ini telah berhasil membuat laman web WalisongoTV serta berhasil memancarkan siaran WalisongoTV melalui fasilitas video live streaming.
\end{abstract}

Kata Kunci: Stasiun televisi daring, Ustream, video live streaming, WalisongoTV.

ISSN 2715-0143 (online) ISSN 2714-9048 (print)

http://journal.walisongo.ac.id/index.php/jit/index

WJIT : Walisongo Journal of Information Technology 


\section{PENDAHULUAN}

Televisi adalah media yang paling luas dikonsumsi oleh masyarakat dunia dan khususnya Indonesia yang jauh dari budaya baca tulis. Televisi menjadi satu-satunya perlengkapan rumah tangga yang dimiliki setiap keluarga betapapun miskinnya keluarga itu, seolah-olah televisi adalah sesuatu yang wajib dimiliki. Berdasarkan penelusuran Nielsen Audience Measurement pada tahun 2012 lalu, 94 persen masyarakat Indonesia mengkonsumsi media melalui televisi. (www.tempo.co).

Televisi sebagai salah satu hasil karya teknologi komunikasi memiliki berbagai kelebihan, baik dari sisi programatis maupun teknologis. Dilihat dari sisi dakwah, media televisi dengan berbagai kelebihan dan kekuatannya seharusnya bisa menjadi media dakwah yang efektif jika dikelola dan dipergunakan secara profesional. Siaran dakwah di televisi sudah mendapatkan tempat tersendiri di kalangan pemirsa. Hasil monitoring langsung terhadap penonton televisi nasional, yang diumumkan pada konferensi pers MUI, KPI dan Kominfo pada 22 Agustus 2011 mengatakan bahwa tayangan dakwah merupakan tipe program yang paling sering ditonton oleh masyarakat. Acara ini dianggap oleh masyarakat dapat menambah pengetahuan, menghibur dan mendidik. Hasil ini diperoleh dari wawancara langsung kepada 200 penonton di 10 kota besar di Indonesia, oleh Komisi Penyiaran
Indonesia (KPI) pada 9-13 Agustus 2011. (www.republika.co.id) Memasuki era teknologi informasi, para pemilik stasiun televisi pun berlomba untuk menarik perhatian para pengguna internet. Maka dibuatlah siaran-siaran televisi yang disiarkan melalui media internet secara daring. Siaran semacam ini disebut dengan streaming. Siaran televisi daring ini menyasar para pengguna internet yang sangat banyak di Indonesia.

Berdasarkan hasil survei Asosiasi Penyelenggara Jasa Internet Indonesia (APJII), jumlah pengguna internet di Indonesia di tahun 2012 ini sudah mencapai angka 63 juta. Penetrasinya sudah mencapai $24,23 \%$ dari total populasi penduduk Indonesia. Perkembangan jumlah pengguna internet terus mengalami peningkatan. Tahun 2009 tercatat jumlah pengguna Internet di Indonesia berjumlah 30 juta pengguna, 2010 sebanyak 42 juta, 2011 mencapai 55 juta, dan di 2012 ini mencapai 63 juta. Dengan potensi seperti itu, maka sangat tepat jika stasiun televisi memperluas jangkauan siarannya melalui jaringan internet.

Dengan realitas yang tersebut di atas, internet memberikan peluang yang sangat baik bagi dunia dakwah. Dakwah Islam di internet bisa menjadi sangat luar biasa, masif dan progresif karena berpotensi diakses oleh jutaan, bahkan milyaran manusia di seluruh dunia. Stasiun televisi dakwah juga sudah selayaknya memanfaatkan jaringan internet ini. Dengan menggunakan teknologi video live 
streaming, siaran dakwah Islam dapat disaksikan oleh jutaan manusia di seluruh dunia.

Fakultas Dakwah dan Komunikasi UIN Walisongo sebagai sebuah institusi yang ikut bertanggung jawab atas berhasilnya dakwah Islam di Indonesia sangatlah tepat untuk menggunakan televisi sebagai salah satu media dakwahnya. Dengan media televisi diharapkan dakwah akan lebih mudah merasuk dalam jiwa masyarakat untuk kemudian mempengaruhi perilaku masyarakat sesuai dengan ajaran Islam. Siaran televisi dakwah ini akan menjadi lebih mudah diakses oleh masyarakat jika disiarkan juga melalui jaringan internet dengan memanfaatkan video live streaming. Keberadaan televisi komunitas di Fakultas Dakwah dan Komunikasi sudah mulai dirintis pada tahun 2012. Televisi komunitas ini bernama Walisongo TV. Sebagai sebuah stasiun televisi yang baru dirintis, banyak aspek yang perlu dipersiapkan dengan baik. Saat ini proses pendirian Walisongo TV sedang dalam tahap pengajuan izin penyiaran. Proses perizinan ini memakan waktu yang cukup lama. Selama surat izin belum turun, Walisongo TV belum boleh memancarkan siarannya. Saat izin penyiaran turun nantinya, Walisongo TV hanya diperbolehkan memancarkan siarannya dalam radius 2,5 kilometer dari titik pemancarnya. Radius 2,5 kilometer ini tentu saja sangatlah sempit bagi sebuah stasiun televisi.
Berdasarkan latar belakang di atas penelitian berjudul "Perancangan Stasiun Televisi Daring untuk Memperluas Jangkauan Siar WalisongoTV" ini diajukan. Penelitian ini bertujuan untuk merancang sebuah website yang memungkinkan acara-acara WalisongoTV dapat dipancarkan secara live streaming. Dengan membangun video live streaming, Walisongo TV mendapatkan dua keuntungan sekaligus. Pertama, Walisongo TV bisa memancarkan siarannya meskipun surat izin penyiaran belum turun. Hal ini bisa terjadi karena untuk membangun video live streaming tidak memerlukan izin khusus. Kedua, jangkauan siar Walisongo TV menjadi jauh lebih luas. Dengan video live streaming, siaran Walisongo TV dapat dipancarkan melalui jaringan internet. Dengan demikian, siaran Walisongo TV dapat disaksikan oleh pemirsa dari seluruh dunia.

\section{KERANGKA TEORI}

Kajian tentang televisi seperti pada WalisongoTV tentu tidak bisa tinggalkan dari ilmu induknya, yakni Ilmu Komunikasi. Carl Hovland adalah orang yang dikenal sebagai perumus Ilmu Komunikasi/Communication Science. Menurutnya Science of Communication is a systematic attempt to formulate in rigorous fashion the principles by which information in transmitted and opinions and attitudes formed". Menurutnya, Ilmu Komunikasi adalah suatu sistem yang berusaha menyusun prinsip-prinsip dalam bentuk yang tepat mengenai hal memindahkan penerangan dan 
membentuk pendapat dan sikap. Adapun komunikasi sebagai suatu gejala diartikan Carl Hovland :" as the process by which an individual (the communicator) transmits stimuly (usually verbal symbols) to modify the behavior other individuals (comunicatees)". (Sunarjo: 1983).

Televisi sebagai sebuah media komunikasi massa memiliki kekuatan ekstra besar dalam mengatasi jarak fisik dan kejiwaan antar manusia, televisi memberi kontribusi yang tidak kecil manfaatnya bagi pengembangan kepribadian manusia. Dan planet bumi kita seakan tidak mengenal batas geografi ataupun rambu lain, ketika media (TV) mengupayakan terbentuknya solidaritas massa, lewat berbagai bentuk pelayanan media. Sebagai salah satu bentuk media massa, televisi juga berfungsi memperkokoh kaidah-kaidah sosial. Dalam hal itu, media massa Islam relevan untuk diberi peranan. Dengan kata lain media Islam dapat melaksanakannya melalui fungsi kritik atau pengawasan sosial (social control) dengan cara verbal maupun tidak verbal, tetapi menghindari ungkapan dan adegan yang bertentangan dengan Al Qur'an dan Sunnah Rasulullah.

\subsection{Media Massa Islam dan Prospeknya \\ Jika dilihat dari jumlah umat} Islam di Indonesia maka media massa Islam sebenarnya memiliki prospek yang cerah. Namun demikian, prospek cerah tersebut masih tergantung pada bagaimana mengelola media massa yang berciri Islam tersebut.Umat tentunya akan melakukan seleksi terhadap segala media yang ditawarkan, untuk selanjutnya dipilih yang benar-benar sesuai dengan kebutuhannya.

Mengelola media penyiaran (seperti televisi dan radio) ataupun media cetak (majalah, surat kabar, bulletin) tidaklah mudah. Diperlukan banyak aspek agar media tersebut dapat bertahan lama dan mendapatkan keuntungan, baik material maupun non material. Berbagai aspek itu diantaranya adalah: modal, peralatan (equipment), sumber daya manusia, network, dan kesungguhan. Di samping itu perlu pemahaman tentang sasaran atau segmentasi yang akan dituju media. Bagaimana kondisi socio cultural mereka, gaya hidup, tingkat pendidikan serta tingkat ekonominya.

\subsection{Unsur Media dalam Proses Dakwah}

Pemanfaatan media untuk kepentingan dakwah merupakan suatu keharusan untuk terwujudnya tujuan dakwah. Pemanfaatan media massa dapat kita lakukan jika kita mampu mengoptimalkan sumberdaya yang kita miliki. Hal ini berarti kita harus menguasai seluk beluk dan praktek-praktek komunikasi antar manusia. Komunikasi antar manusia pada dasarnya adalah suatu proses interaksi antara komunikator dan komunikan dengan tujuan untuk mencapai suatu kesamaan pengertian, pemahaman dan pengamalan mengenai isi pesan tersebut. 
Demikian juga dengan dakwah, sebagai salah satu bentuk komunikasi, dakwah berarti menyampaikan sesuatu kepada orang lain yang bersifat mengajak untuk mengubah suatu keadaan yang tidak baik menjadi suatu keadaan yang baik dan terpuji. Sebagai bentuk dakwah yang modern, seorang da'i harus memiliki kreativitas mengeksplorasi bentuk dakwah yang menarik, bervariasasi dan enak dinikmati.

Tugas profetika dakwah memiliki jangkuan luas ke depan terutama untuk mengatasi persi permasalahan dakwah yang saat ini tengah menggejala di masyarakat dan bahkan masih akan terus bererkembang. Secara substansial, profetika dakwah memiliki beberapa ciri, antara lain: 1). Dakwah yang multidialogis dan 2). Dakwah yang integratif dan fungsional.

Dalam kerangka kegiatan yang multidialogis, dakwah sejatinya dapat berperan sebagai proses interaksi kaum musimin dengan umat manusia secara keseluruhan, suatu interaksi yang bertujuan memperkenalkan nilai-nilai Islam dan konsep-konsep islami secar lebih operasional sekaligus mengupayakan realisasinya dalam kehidupan umat manusia dalam segala aspeknya, baik pada tingakat individu maupun komunitas.

Karena itu, untuk menjawab berbagai tantangan ke depan, baik secara akademis maupun prakmatis, program pengembangan dakwah dituntut mampu menawarkan alternatif yang dapat menyampaikan pesan-pesan Islami dalam format sajian dakwah yang lebih relevan dengan perkembangan teknologi informasi dan komunikasi.

\subsection{Ragam Bentuk Media Massa}

Media massa merupakan alat bantu utama dalam proses komunikasi massa. Komunikasi massa secara sederhana berarti kegiatan komunikasi yang menggunakan media (communicating with media). Menurut Bittner media massa merupakan suatu komunikasi yang dilakukan melalui perantara media kepada sejumlah orang yang tersebar di tempat-tempat yang tidak ditentukan. (Bittner: 1986). Jadi media massa adalah suatu alat transmisi informasi, seperti koran, majalah, buku, film, radio, dan televisi, atau suatu kombinasi bentuk dari bentuk-bentuk media itu sendiri.

Lewat penemuan teknologi komunikasi dan informasi yang dari waktu ke waktu semakin berkembang pesat, media massa memiliki peluang yang besar untuk memenuhi hampir setiap kebutuhan dan keinginan manusia. Televisi misalnya, di samping jumlah stasiun yang semakin banyak, jam tayang televisi kini juga semakin bertambah lama dengan sajian acaranya yang sangat bervariasi.

Pada dasarnya, pertumbuhan media massa terjadi karena dipengaruhi oleh beberapa unsur yang saling mempengaruhi, di antaranya adalah masyarakat sebagai pengguna, pemerintah sebagai regulator dan pengusaha. Ada 2 macam media massa yang berkembang pesat saat ini: media 
cetak (surat kabar, majalah, buku) dan media elektronik (radio dan televisi).

Perkembangan media

komunikasi modern dewasa ini telah memungkinkan orang diseluruh dunia untuk saling berkomunikasi. Hal ini terjadi karena sangat dimungkinkan adanya berbagai channel (media) yang dapat digunakan sebagai sarana penyampaian pesan. Media penyiaran, yaitu radio dan televise merupakan contoh media massa yang efisien dalam mencapai audiennya dalam jumlah yang sangat banyak. Karena itu media penyiaran memegang peranan yang sangat penting dalam Ilmu Komunikasi, khususnya Ilmu Komunikasi Massa.

\subsection{Konsep Dakwah}

Dakwah secara essensi memiliki satu kata kunci yakni ishlah atau perbaikan. Perbaikan yang dimaksudkan di sini adalah perbaikan dalam perspektif Islam dan perbaikan dalam arti sebuah proses yang terarah dan berkesinambungan. Dalam perspektif Islam dakwah berarti sebuah proses untuk mengajak seluruh manusia dari penghambaan kepada makhluk menuju penghambaan kepada Allah semata secara paripurna.

Konsep mendasar dakwah pada dasarnya tunggal, yaitu mengajak manusia untuk bersama menuju ke jalan Tuhan (ud'u ila sabili rabbik). Namun demikian, dalam bentuknya yang aktual, konsep tunggal itu kemudian ditafsirkan oleh umat Islam melalui proses dialektika kultural-kontekstual dengan warna yang beraneka ragam.

Dakwah merupakan aktivitas yang sangat penting dalam Islam. Dengan dakwah, Islam dapat tersebar luas di seluruh penjuru dunia. Dalam kehidupan masyarakat, dakwah berfungsi menata kehidupan yang agamis menuju masyarakat yang harmonis dan bahagia.

Ditinjau dari segi bahasa, kata dakwah berasal dari bahasa Arab, yaitu $d a^{\prime} a, y a d^{\prime} u$ yang berati panggilan, ajakan, seruan. Secara termininologi, para ahli berbeda-beda dalam memberikan pengertian tentang dakwah Islam. Ada yang mengartikan dakwah Islam sebagai transformasi sosial ada yang mengartikan dakwah secara normatif yakni mengajak manusia kejalan kebaikan dan petunjuk untuk memperoleh kebahagiaan di dunia dan akhirat.

Meskipun terjadi perbedaan tentang definisi dakwah di antara para ahli, namun dapat di tarik kesimpulan, bahwa pada dasarnya dakwah adalah aktualisasi teologis (iman yang dimanifestasikan dalam semua sistem kegiatan kemasayarakatan).

Dakwah Islam juga bersifat universal, artinya adalah bahwa obyeknya (sasaran dakwah/mad'u) adalah semua manusia tanpa mengenal batasan. Islam mengandung ajaran-ajaran dasar yang berlaku untuk semua tempat dan zaman. Dasar-dasar ajaran Islam yang mengandung nilai-nilai universal antara lain berkaitan dengan tauhid, etika, moral, bentuk dan sistem pemerintahan, sosial politik dan 
ekonomi, partisipasi demokrasi, keadilan sosial perdamain, pendidikan dan intelektualisme, etos kerja, lingkungan hidup dan lain sebagainya. (Aziz: 2004).

Agar dakwah mencapai sasaran strategis jangka panjang, maka tentunya dibutuhkan suatu metode yang representatif disesuaikan dengan kondisi dan situasi mad'u. Dalam al-Qur'an telah dijelaskan beberapa metode yang bisa diterapkan oleh para da'i. Seperti yang tertuang dalam QS. An-Nahl ayat 125.

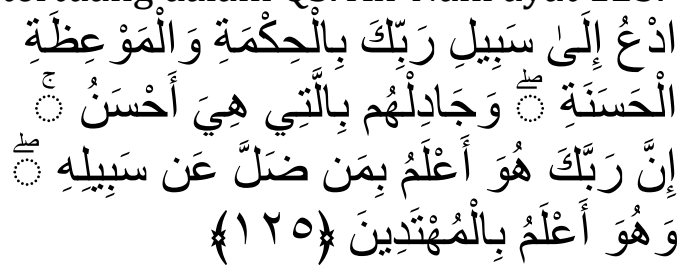

Artinya:

Serulah manusia kepada jalan Tuhanmu dengan hikmah dan pelajaran yang baik dan bantahlah mereka dengan cara yang baik. Sesungguhnya Tuhanmu Dialah yang mengetahui siapa yang tersesat dari jalan-Nya dan Dialah yang mengetahui orang-orang yang mendapatkan petunjuk.

Dari ayat tersebut secara garis besar ada tiga pokok metode (thariqah) dakwah, yaitu:

1. Hikmah, yaitu berdakwah dengsn memperhatikan situasi dan kondisi sasaran dakwah dengan menitik beratkan pada kemampuan mereka, sehingga dalam menjalankan ajaran-ajaran Islam selanjutnya mereka tidak lagi merasa terpaksa atau keberatan.

2. Mauidhaah Hasanah, yaitu berdakwah dengan memberikan nasihat-nasihat atau menyampaikan ajaran-ajaran Islam dengan rasa kasih sayang, sehingga ajaran Islam yang sampaikan itu dapat menyentuh hati mereka.

3. Mujadalah, yaitu berdakwah dengan cara bertukar fikiran dan membantah dengan cara yang sebaik-baiknya dengan tidak memberikan tekanan-tekanan dan tidak pula dengan menjalankan yang menjadi sasaran dakwah.

2.5. Media (Wasilah) Dakwah dan Jenis-Jenisnya

Kata media berasal dari bahasa Latin, median, yang merupakan bentuk dari medium secara etimologi berarti perantara. Wilbur Schramm mendefinisikan media sebagai teknonologi informasi yang dapat digunakan dalam pengajaran. (Amin: 2009). Secara lebih spesifik yang dimaksud media dalam hal ini adalah lat-alat fisik yang digunakan untuk menjelaskan isi pesan atau pengajaran, seperti buku, film, televisi, video dan lain sebagainya.

Media dakwah adalah peralatan yang digunakan untuk menyampaikan materi dakwah kepada penerima dakwah. Media dakwah merupakan bagian dari unsur dakwah. Adapun unsur-unsur dakwah yang lainnya adalah da'i, mad'u, maddah, wasilah, thariqah dan atsar. Dengan demikian media adalah alat yang digunakan untuk menyampaikan materi dakwah (ajaran Islam) kepada mad'u.

Pada dasarnya dakwah dapat menggunakan berbagai wasilah yang 
dapat membuat sasaran dakwah menerima apa yang disampaikan oleh mad'u. Semakin tepat dan efektif wasilah yang dipakai maka semakin efektif pula pemahaman ajaran Islam yang disampaikan pada mayarakat sasaran dakwah.

Untuk menyampaikan ajaran Islam kepada mad'u, dakwah dapat menggunakan beberapa wasilah. Hamzah Ya'qub membagi wasilah dakwah menjadi lima macam: lisan,tulisan, lukisan, audio visual dan akhlak:

1. Lisan merupakan dakwah yang paling yang menggunakan suara, dakwah dengan wasilah ini dapat berbentuk pidato, ceramah, kuliah, bimbingan, penyuluhan dan sebagainya.

2. Tulisan merupakan pesan dakwah dalam bentuk tulisan. Seperti buku, majalah bulletin, surat kabar, jurnal dan lain sebagainya.

3. Lukisan, gambar, karikatur dan sebaginya

4. Audio visual, yaitu media dakwah yang merangsang indra pendengaran dan penglihatan melalui televisi, film, internet dan lain sebagainya

5. Akhlaq, yaitu perbuatan-perbuatan nyata yang mencerminkan ajaran Islam yang dapat dinikmati serta didengarkan oleh mad'u

Secara umum media-media yang dapat digunakan sebagai media dakwah dapat dikelompokkan pada:

a. Media Visual

Adalah bahan-bahan atau alat yang dapat dioperasikan untuk kepentingan dakwah melalui indra penglihatan. Perangkat media visual yang dapat untuk kepentingan dakwah adalah gambar, karikatur, foto dan lain sebagainya.

b. Media Audio

Alat- alat yang dapat dijadikan sebagai sarana penunjang kegiatan dakwah yang ditangkap melalui indra pendengaran. Media audio sudah biasa digunakan orang untuk berbagai kegiatan. Dengan media audio komunikasi dapat berlangsung tanpa batas jarak. Yang termasuk media audio adalah Radio dan tape recorder.

c. Media Audio Visual

Adalah media penyampain informasi dan pesan yang dapat menampilkan unsur gambar (visual) dan suara (audio) secara bersamaan pada saat mengkomunikasikan pesan dan informasi. Dengan demikian, bisa dikatakan bahwa media audio visual lebih sempurna jika dibanding dengan media audio dan media visual saja. Adapun yang termasuk media audio visual ini antara lain adalah televisi, film, sinetrron dan video.

d. Media Cetak (printed publications)

Adalah media yang digunakan untuk menyampaikan pesan atau informasi melalui tulisan yang tercetak. Media cetak menggunakan segala macam yang dicetak di kertas. Yang temasuk media cetak ini antara lain adalah majalah, bulletin, jurnal, buku, brosur, surat kabar dan lain sebagainya. (Amin: 2009).

Televisi merupakan media audio visual yang sangat efektif dalam menyebarkan informasi kepada khalayak atau pemirsa, karena melalui televisi pesan-pesan dakwah dapat 
tersampaikan dengan jangkauan yang sangat luas. Gerbner, Pakar komunikasi dan peneliti televisi Amerika, menyebutkan bahwa televisi adalah agama masyarakat industry. Televisi menggeser agama-agama konvensional, khutbahnya didengar dan disaksikan oleh jamaah yang lebih besar dari jamah agama mana pun, ritus-ritusnya diikuti dengan penuh kekhitmatan dan lebih banyak menggetarkan hati dan mempengaruhi bawah sadar manusia daripada ibadah-ibadah keagamaan. (Rakhmat: 1991).

\subsection{Video Streaming}

Dalam perkembangan teknologi informasi, streaming lebih mengarah pada sebuah teknologi yang mampu melakukan kompresi terhadap ukuran file baik audio maupun video dengan tujuan agar mudah ditransfer melalui jaringan lokal maupun internet. Pada suatu jaringan, antar komputer dapat melakukan pertukaran file dengan cara sharing yaitu dengan mengambil file dari komputer satu lalu setelah keseluruhan file terkirim, komputer penerima dapat menampilkan file yang dikirim dari komputer pengirim.

Dari sudut pandang pemirsa, video streaming dapat diartikan sebagai sebuah teknologi di mana pemirsa dapat memutar file video tanpa harus menyimpannya ke dalam hardisk. File video yang akan disiarkan oleh stasiun televisi disimpan dalam sebuah komputer server. Pemirsa melakukan request untuk memutar file video tersebut. Proses pengiriman file video dari server ke pemirsa inilah yang disebut video streaming.

Video streaming dapat diartikan sebagai suatu metode yang memanfaatkan streaming server untuk mentransmisikan digital video melalui suatu jaringan data sehingga memungkinkan video playback dapat langsung dilakukan tanpa perlu menunggu sampai proses download selesai ataupun menyimpannya terlebih dahulu di komputer client. Sistem video streaming melibatkan proses encoding terhadap isi dari data video, dan kemudian mentransmisikan video stream melalui suatu jaringan (berkabel ataupun nirkabel), sehingga client tujuan dapat mengakses, melakukan decoding, dan memunculkan video tersebut secara realtime.

Video streaming dapat digunakan di banyak aplikasi, seperti video conference, e-learning atau distance learning, video pengawas (video surveillance), remote monitoring, dan lain-lain. Kehadiran jaringan yang memungkinkan server sebagai video source dapat terpisah jarak secara fisik dari client merupakan faktor pembeda video streaming dari pre-recorded video yang sudah umum digunakan oleh konsumen elektronik, seperti CD/DVD. Oleh sebab itu video streaming memiliki karakteristik utama sebagai berikut :

a. Teknologi streaming memungkinkan akses realtime ataupun on-demand.

b. Data streaming ditransmisikan dari sisi server, playback segera dilakukan di sisi client setelah 
diterima dan diproses terlebih dahulu.

c. Tidak meninggalkan data residu di sisi client setelah proses streaming selesai.

\begin{tabular}{lrr}
\multicolumn{2}{c}{ Teknologi } & streaming \\
cenderung & bersifat & bandwidth- \\
dependent, & sehingga & sangat
\end{tabular} bergantung pada kondisi jaringan. Agar data stream dapat di-playback secara baik, perlu diperhatikan beberapa pertimbangan supaya data stream memiliki bit rate/data transfer rate yang cukup rendah, karena dengan mengurangi bit rate berarti sama saja dengan mengirimkan lebih sedikit data. Mengurangi bit rate dapat dilakukan dengan cara antara lain:

a. Membuat dimensi frame video menjadi lebih kecil.

b. Membuat jumlah frame per second (fps) video menjadi lebih rendah.

Mengurangi jumlah informasi yang ada di setiap frame video melalui proses kompresi.

\section{METODE}

Metode yang digunakan dalam perancangan stasiun televisi daring ini terdiri dari tiga tahap. Tahap pertama adalah perancangan website WalisongoTV. Website ini dipergunakan sebagai tempat untuk memancarkan siaran WalisongoTV ke dunia internet. Seluruh isi siaran WalisongoTV nantinya akan diletakkan di dalam website ini.

Tahap kedua adalah perancangan video live streaming. Pada tahap ini, dirancang isi utama dari website WalisongoTV. Isi utama ini adalah video live streaming yang merupakan siaran yang langsung dipancarkan dari studio WalisongoTV. Langkah-langkah yang dilakukan pada tahap ini yaitu perancangan laman live streaming dan perancangan server streaming.

Tahap ketiga adalah uji coba video live streaming. Tahap ini dimaksudkan untuk mengetahui hasil dari perancangan stasiun televisi daring. Ada tiga uji coba yang dilakukan pada tahap ini, yaitu uji coba menggunakan Ustream Broadcaster, menggunakan Ustream Producer dan menggunakan VLC Player.

\section{PERANCANGAN WEBSITE WALISONGO TV}

Website WalisongoTV dimanfaatkan untuk memancarkan siarannya ke ranah internet. Dengan menggunakan website, siaran WalisongoTV dapat disaksikan oleh pemirsa dari seluruh dunia. Tahaptahap perancangan website terdiri dari pembuatan email, pembuatan website WalisongoTV, pengaturan tampilan website. perancangan laman website dan pembuatan pos.

WalisongoTV harus mempunyai email untuk bisa membuat website. Untuk pembuatan email ini dipilih server email yang disediakan oleh google (gmail). Gmail ini dipilih karena fleksibilitasnya yang tinggi dan merupakan salah satu layanan email terbaik pada saat ini. Pembuatan akun gmail ini juga sekaligus bisa dimanfaatkan untuk mengakses semua layanan google. Dengan demikian apabila dalam pengembangan website video live 
streaming nantinya memerlukan fasilitas-fasilitas tambahan yang disediakan oleh google, maka fasilitas itu dapat didapatkan dengan cepat dan mudah.

Untuk pembuatan website WalisongoTV dipilih fasilitas gratis yang disediakan oleh google berupa weblog atau blog. Website WalisongoTV dirancang memiliki tiga laman utama, yaitu Beranda, Video dan Live Streaming. Selain itu juga dibuat satu laman khusus yang berisi profil dan sejarah WalisongoTV. Tiga halaman utama akan ditampilkan pada menu utama di bagian atas. Sedangkan laman profil akan ditampilkan pada menu profil di sebelah kanan laman utama.

Laman beranda nantinya akan diisi dengan berita-berita terkini dan informasi-informasi yang berkaitan dengan UIN Walisongo. Laman Video akan diisi dengan videovideo yang dihasilkan oleh rumah produksi WalisongoTV. Video-video ini dapat langsung dilihat dengan cara mengeklik pada video yang diinginkan. Sedangkan laman yang ketiga yaitu laman Live Streaming berisi siaran langsung (live) dari studio WalisongoTV. Siaran ini dapat dilihat secara langsung oleh pemirsa pada saat WalisongoTV mengudara. Laman khusus profil diisi dengan profil dan sejarah singkat perkembangan WalisongoTV. Tampilan laman beranda dapat dilihat dalam gambar 1 . Sedangkan gambar 2 menunjukkan tampilan laman video.

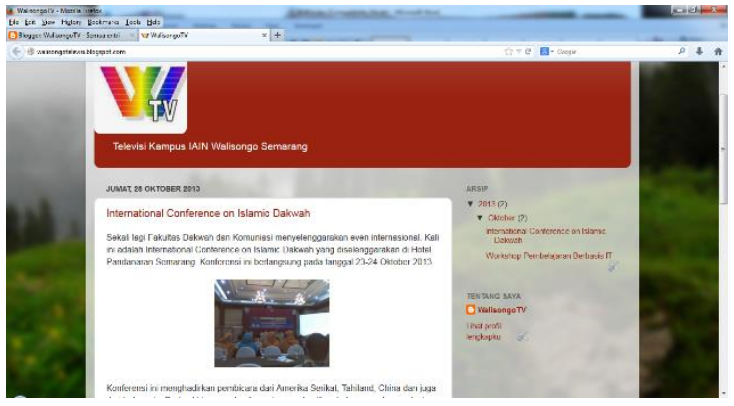

Gambar 1. Tampilan Laman Beranda

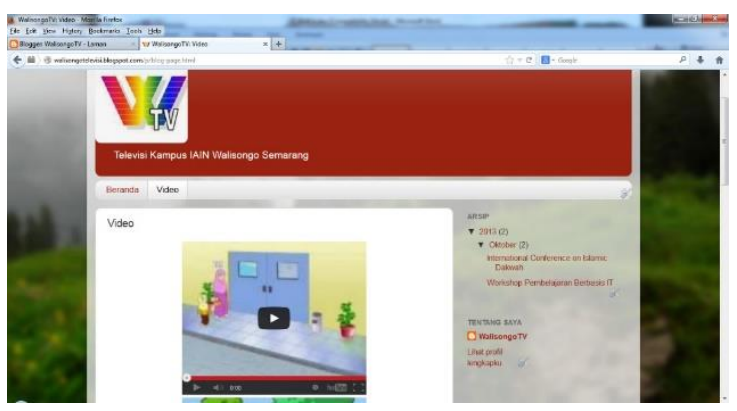

Gambar 2. Tampilan Laman Video

\section{PERANCANGAN VIDEO LIVE STREAMING}

Melalui video live streaming, WalisongoTV bisa memancarkan siarannya melalui internet. Dengan demikian siaran WalisongoTV dapat disaksikan oleh pemirsa di seluruh dunia. Perancangan video live streaming terdiri dari tahap perancangan server streaming, setelan server streaming dan perancangan laman live streaming.

Dalam pembuatan website video live streaming, salah satu hal yang wajib dipersiapkan adalah server streaming. Untuk WalisongoTV dipilih server gratis yang disediakan oleh ustream. Agar dapat menggunakan fasilitas ustream, pengguna diharuskan membuat akun di ustream. WalisongoTV membuat akun di ustream dengan nama walisongotelevisi. Setelah membuat 
akun, selanjutnya WalisongoTV membuat kanal baru dengan nama Walisongo TV. Server ustream masih perlu disetel sedemikian rupa agar bisa digunakan untuk memancarkan siaran WalisongoTV.

Agar siaran WalisongoTV dapat disaksikan oleh pemirsa di website yang telah dibuat, maka perlu disediakan satu laman khusus untuk memancarkan siaran. Laman ini diberi nama "live streaming". Laman live streaming merupakan sarana bagi para pemirsa WalisongoTV untuk melihat secara langsung acara yang sedang disiarkan oleh WalisongoTV. Laman ini akan berisi jendela mirip dengan televisi yang layarnya menampilkan acara dari WalisongoTV. Laman live streaming disisipkan pada website yang telah dibuat sebelumnya.

Untuk bisa menampilkan siaran WalisongoTV, laman live streaming akan diisi dengan kodekode HTML yang merupakan hasil setelan server streaming yang digunakan. Dalam hal ini WalisongoTV menggunakan server Ustream. Ada beberapa baris kode HTML dari ustream yang dipakai untuk menampilkan saluran WalisongoTV. Kode ini didapatkan dari ustream.

Laman live streaming sudah bisa diakses oleh pemirsa WalisongoTV. Laman ini bisa dilihat dengan cara mengeklik tombol "live streaming" di bagian atas website. Pada laman ini terdapat pemutar (player) video yang akan menampilkan siaran dari WalisongoTV. Siaran ini dapat diakses oleh pemirsa hanya ketika WalisongoTV menyelenggarakan siaran. Gambar 3 menunjukkan tampilan laman live streaming di website WalisongoTV.

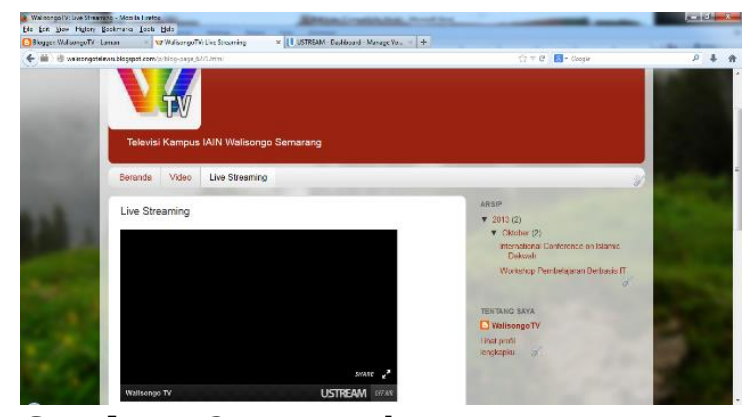

Gambar 3. Tampilan Laman Live Streaming

\section{UJI COBA VIDEO LIVE STREAMING}

Uji coba siaran dimaksudkan untuk mengetahui tingkat keberhasilan perancangan video live streaming yang dilakukan. Uji coba siaran dilakukan dengan menggunakan beberapa cara yaitu dengan menggunakan ustream broadcaster, menggunakan ustream producer dan menggunakan VLC player. Uji coba siaran dilakukan di Laboratorium Dakwah UIN Walisongo. Komputer pemancar adalah laptop yang terkoneksi dengan jaringan internet UIN Walisongo menggunakan wifi. Sedangkan komputer penerima adalah komputer desktop dengan yang terkoneksi ke jaringan internet UIN Walisongo menggunakan kabel.

Siaran dengan menggunakan webcam sebagai sumber video dapat dilakukan tanpa software tambahan. Untuk melakukannya administrator masuk ke server ustream kemudian 
login menggunakan akun walisongotelevisi. Pada server ustream dipilih menu "go live" untuk memulai siaran dengan menggunakan ustream broadcaster.

Uji coba kedua menggunakan ustream producer untuk melakukan siaran. Ustream producer merupakan software yang berfungsi sebagai alat untuk memproduksi dan mengelola video dan atau audio yang akan dipancarkan melalui server ustream. Ustream producer mengatur sumber video dan audio, apakah dari kamera, dari file di hardisk atau dari gambar layar komputer.

Ada tiga cara siaran yang bisa dikelola menggunakan ustream. Tiga cara itu adalah siaran menggunakan kamera, menggunakan file dan menggunakan tampilan desktop. Cara yang pertama adalah siaran menggunakan kamera. Siaran ini bisa menggunakan kamera apa saja yang terhubung ke komputer. Cara kedua dalam siaran menggunakan ustream producer adalah dengan menggunakan file sebagai sumber siaran. File siaran diambil dari dalam hardisk komputer pemancar. Siaran dengan menggunakan tampilan desktop menjadi cara yang ketiga. Ustream producer mampu melakukan hal ini karena ditunjang oleh fasilitas desktop presenter. Fasilitas ini digunakan untuk mengambil gambar tampilan desktop dan selanjutnya memancarkannya melalui server ustream.

Uji coba siaran berikutnya menggunakan VLC Player sebagai pemutar file video. VLC Player merupakan program pemutar video yang dapat memutar hampir semua jenis file video. VLC Player juga dilengkapi dengan berbagai fitur yang cukup lengkap. Salah satu fitur yang cukup penting adalag fitur untuk memberikan efek pada audio dan video. VLC Player nantinya akan dipakai untuk membuat playlist, memutar file video dan memberikan logo Walisongo TV pada layar.

Hasil uji coba siaran dapat dilihat dalam gambar 4 dan 5 . Siaran dengan menggunakan webcam ditunjukkan dalam gambar 4 . Sedangkan gambar 5 memperlihatkan tampilan website saat siaran menggunakan file video.

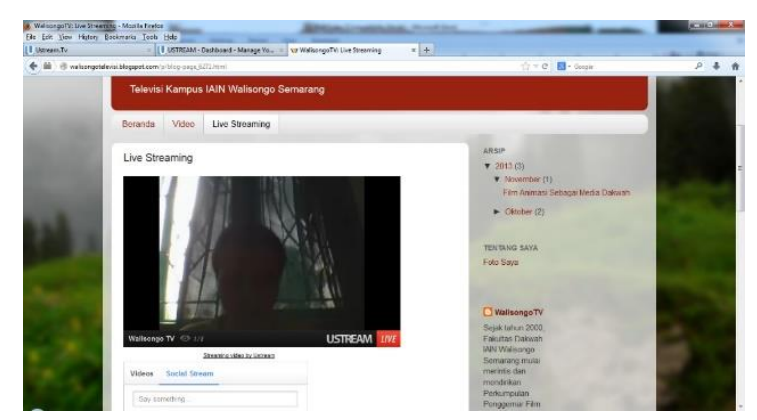

Gambar 4. Siaran Menggunakan Webcam

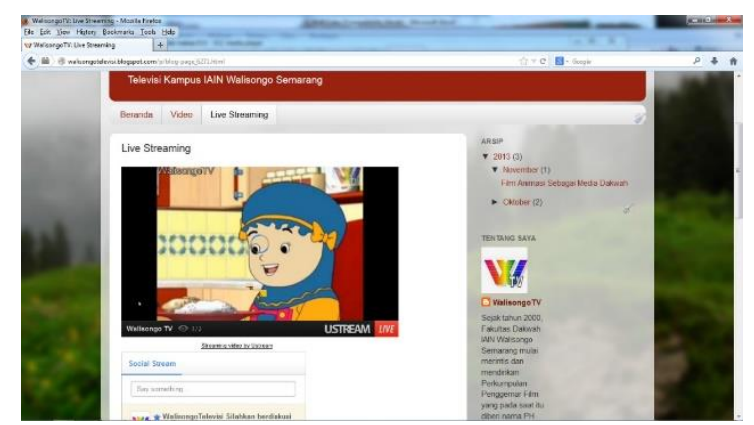

Gambar 5. Siaran Menggunakan File Video

\section{PENUTUP}

Dari penelitian yang telah dilakukan dapat ditarik kesimpulan 
bahwa website WalisongoTV telah berhasil dibuat dan berjalan dengan baik. Website ini terdiri dari tiga laman yaitu laman beranda, video dan live streaming. Laman beranda berisi artikel-artikel up to date yang berkaitan dengan UIN Walisongo. Laman video berisi file-file video produksi WalisongoTV. Sedangkan laman live streaming merupakan laman yang digunakan untuk memancarkan siaran WalisongoTV. Website WalisongoTV masih berbentuk weblog dengan alamat http://walisongotelevisi.blogspot.co m.

Proses siaran video live streaming dapat berjalan dengan baik dengan kualitas gambar dan suara yang bagus. Siaran yang dipancarkan bisa bersumber dari kamera langsung maupun dari file video. Dalam proses penyiaran digunakan software perantara yaitu ustream producer dan VLC Player. Siaran melalui webcam dapat dilakukan tanpa software perantara tersebut. Siaran live streaming berhasil dilakukan di website WalisongoTV. Sistem penyiaran video live streaming yang dibangun masih memiliki beberapa kekurangan. Penyiaran menggunakan kamera baru bisa menangkap gambar dari satu kamera saja. Pada saat siaran menggunakan file video, pengeditan playlist mengalami sedikit kesulitan apabila dilakukan saat siaran berlangsung. Kelemahan paling mencolok dari sistem penyiaran yang dibangun adalah delay yang cukup lama. Penyebab utamanya adalah keterbatasan bandwidth yang dimiliki oleh UIN Walisongo.

Untuk mengatasi berbagai kelemahan diperlukan beberapa pengembangan dari sistem video live streaming yang telah dibangun. Website yang telah dibuat hendaknya segera dipindahkan ke server UIN Walisongo di bawah domain walisongo.ac.id. Dengan demikian akan lebih terlihat bahwa ini adalah website resmi WalisongoTV yang merupakan televisi kampus UIN Walisongo. Delay yang cukup lama dapat diatasi dengan penambahan bandwidth pada jaringan internet UIN Walsiongo. Penambahan bandwidth juga bisa dilakukan secara khusus pada komputer pemancar siaran WalisongoTV. Dengan penambahan bandwidth diharapkan delay siaran semakin pendek.

Agar bisa melakukan siaran dari beberapa kamera, bisa digunakan perangkat switcher. Perangkat yang dimaksud di sini bisa berupa switcher dalam bentuk hardware yang terhubung ke komputer, bisa juga dalam bentuk software yang bisa menangkap gambar dari beberapa kamera. Selanjutnya agar operator WalisongoTV bisa melakukan pengeditan playlist dengan mudah pada saat siaran sedang berlangsung, perlu adanya integrasi antara player dengan server. Hendaknya player yang digunakan mempunyai fasilitas streaming yang langsung bisa diintegrasikan dengan server yang digunakan. 


\section{REFERENCES}

Eka Setiawati dan Hani Irmayanti. "Studi Video Streaming untuk Penayangan Aktivitas Matahari di Situs Web Seacara Real Time”. Skripsi, Unikom. Bandung. 2011.

Erna Puspita. "Rancang Bangun Aplikasi Video Streaming pada Jaringan ClientServer". Skripsi, Unikom. Bandung. 2005.

Hendra Kurniawan E. "Aplikasi Web untuk Video Broadcast dengan Jaringan Lokal". Skripsi, Universitas Kristen Petra. Surabaya. 2008.

http://www.apjii.or.id/index.php?option=com_content\&view=article\&id=59\&Ite mid=53. Diakses pada 1 April 2013.

http://www.komisiinformasi.go.id/assets/data/arsip/UU_32_2002_Penyiaran.pd f. Diakses pada 13 Mei 2013.

http://www.republika.co.id/berita/nasional/umum/11/08/22/lqc2nrtayangan-dakwah-favorit-pemirsa-televisi. Diakses pada 13 Mei 2013.

http://www.tempo.co/read/news/2013/03/06/090465467/Acara-TV-IniPaling-Digemari-Penonton-Indonesia. Diakses pada 13 Mei 2013.

M. Alfandi. "Problematika Dakwah Melalui Media Televisi : Perspektif Bisnis Media". Jurnal Ilmu Dakwah, Vol. 24, No. 2. Semarang. 2004.

M. Alfandi. "Televisi dan Pendidikan Anak dalam Keluarga". Jurnal Ilmu Dakwah, Vol. 28, No. 2. Semarang. 2008.

Morissan, M. A. "Manajemen Media Penyiaran : Strategi Mengelola Radio dan Televisi". Kencana. Jakarta. 2008.

Nur Cahyo Hendro W. "Televisi Sebagai Media Dakwah Islami". Jurnal Ilmu Dakwah, Vol. 29, No. 1. Semarang. 2009.

Nur Cahyo Henro W. "Internet Sebagai Media Dakwah Islami di Era Globalisasi”. Jurnal Ilmu Dakwah, Vol. 29, No. 2. Semarang. 2009.

Wan Luptan Azhary. "Rancang Bangun Intranet Video Live Streaming untuk Proses Belajar Mengajar". Proyek Akhir, Institut Teknologi Sepuluh Nopember. Surabaya. 2006. 
This page intentionally left blank. 